\title{
Simulation of the Evacuation of a football stadium using the CA Model PedGo
}

\author{
Hubert Klüpfel $^{1}$ and Tim Meyer-König ${ }^{2}$ \\ 1 TraffGo GmbH \\ Falkstrasse 73-77 - 47057 Duisburg - Germany \\ email: kluepfeletraffgo.com \\ 2 TraffGo GmbH \\ Johannisstraß 42 - 24937 Flensburg - Germany \\ email: m-k@traffgo.com
}

Summary: Computer simulations have become an important tool for analysing egress processes and assessing evacuation concepts. Especially so called microscopic models can by now be considered state of the art.

In this paper we will describe the software PedGo which is based on a 2D cellular automaton and its application to the simulation of evacuations form large and complex structures. The focus is on the practical application to fullscale scenarios. As an example, we show results for the egress from a football stadium.

Keywords: evacuation, egress, simulation, 2D cellular automaton, pedestrian

\section{Description of the CA-model}

PedGo is based on a stochastic Multi-Agent Model where the space is divided into quadratic cells of size $(40 \mathrm{~cm})^{2}$ (cf. Figure 1). Consequently, the time is measured also in discrete steps (identified as $1 \mathrm{~s}$ in reality). Each cell can be either empty, occupied by at most one person, or be non-accessible (e.g. wall or furniture). Since the laws for human behaviour and interaction are not known in detail, PedGo is not based on a first principles approach for human behaviour modelling but the model parameters are rather an estimation of the effective (phenomenological) behaviour of and interaction between individuals.
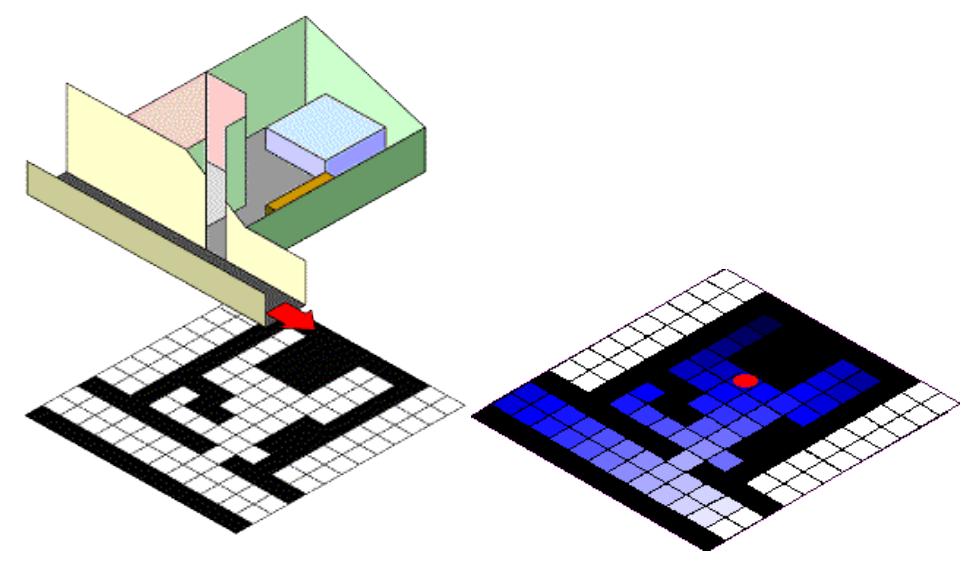
Fig. 1 Representation of the geometry as a grid of cells. The orientation potential is indicated by the shading. The darker the shade is the larger is the distance to the exit.

The orientation of the persons when leaving a building or vessel is usually based on the signage. The routes are represented in the model by a piece of information about the distance to the next exit, respectively destination put into each cell (cf. Figure 1, right).

For complex geometries, several potentials can be defined. Then, the population is divided into groups and each group is assigned to a different potential.

The transition probabilities are then given by:

$$
\begin{aligned}
p_{i} & =e^{-\frac{\left(P_{i}-P_{0}\right)}{S}} \\
p_{i, \text { current direction }} & \rightarrow p_{i, \text { current direction }} \cdot \Theta
\end{aligned}
$$

where $P_{i}$ is the potential value of cell $i, P_{0}$ the potential value for the current cell, and $p_{i}$ is the probability for transition to cell $i$ (without the necessary normalization constant). The so called inertia $\Theta$ favours the movement into the current direction, i.e. every pedestrian has a direction, even if she stands still. The computation of the potential values $P_{i}$ is based on an extended Manhattan metric (with eight neighbouring cells) and an additional smoothing algorithm. Basically, for a hallway with the exit at the left, the potential value is 10 times the distance in cells: If the cell index along the hallway is $i$, then $P_{i}=10 i$. This must of course be in accordance with the choice of the parameter $S$ in the formulas above (see also table 1 and the following section).

\section{Validation of the model and calibration of the parameters}

There is a set of six parameters: $v_{\max }, t_{\text {patience}}, t_{\text {react }}, \mathrm{S}, \mathrm{p}_{\text {orient }}$, and $\Theta . \mathrm{S}$ and $\Theta$ are explained by equations (1) and (2). $v_{\max }$ is the free walking speed, after a pedestrian has been waiting in a queue $(\mathrm{v}=0)$ for the time $t_{\text {patience }}$ he changes his strategy and follows another route (routes are represented by potentials as explained above). The reaction time $t_{\text {react }}$ is the individual off-set before movement starts and finally $p_{\text {orient }}$ is the probability for stopping $(v=0)$, which is applied in every time-step.

The fundamental diagram of the model (for a long hallway) is shown in figure 2. The parameters used in the simulation of the evacuation of the sports stadium can be found in table 1 . For the calculation of the fundamental diagram, the walking speed was set to 2 to 5 cells per time-step and the orientation frequency to 0 to 0.3 . All the other parameters are as in table 1 . 


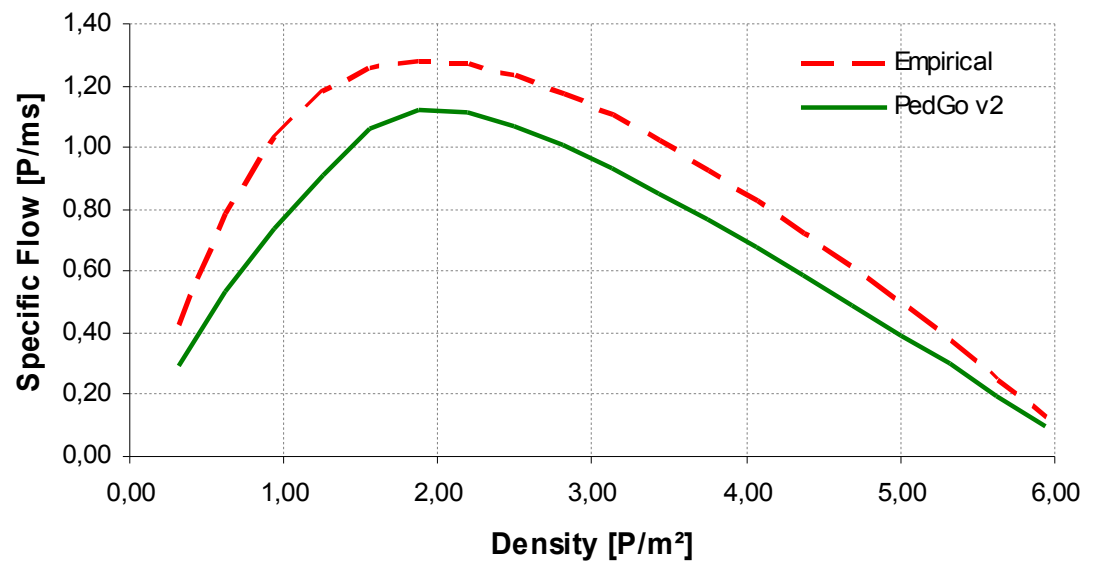

Fig. 2 Fundamental diagram for a hallway with uni-directional flow. Empirical curve adapted from [4].

\section{Simulation of the evacuation of a football stadium}

The structure investigated in this example is a football stadium which consists of seven levels. Of course, these levels can not really be considered floors in the same sense as for, e.g. an office building. However, in order to simulate the process correctly, seven levels had to be defined, since all the stairs are projected on the floor below in the model. Accordingly, the horizontal free walking speed is divided by two on stairs, which is a combination of the reduced walking speed along the incline and the geometrical factor ( $\cos \alpha$, where $\alpha$ is the angle of the stairs).

The parameters used in the simulation are shown in table 1 . The model defined in the previous section is sufficient to simulate also very complex scenarios like the football stadium without additional enhancements. Figure 3 shows simulation results for the stadium.

$\begin{array}{lrrrcc} & \text { Minimum } & \text { Maximum } & \text { Mean } & \begin{array}{c}\text { Standard } \\ \text { Deviation }\end{array} & \text { Unit } \\ \begin{array}{l}\text { Free walking } \\ \text { speed } \mathrm{v}_{\max }\end{array} & 4 & 4 & - & - & \text { cells/s } \\ \begin{array}{l}\text { Patience } \mathrm{t}_{\text {patience }} \\ \text { Sway } \mathrm{S}\end{array} & 5000 & 5000 & - & - & \mathrm{S} \\ & 1 & 5 & 3 & 2 & 0.1 \mathrm{a} \\ \begin{array}{l}\text { Reaction time } \mathrm{t}_{\text {react }} \\ \begin{array}{l}\text { Orientation } \\ \text { frequency }\end{array}\end{array} & 0 & 0 & - & - & \mathrm{S} \\ \text { Inertia } \Theta & 0 & 0 & - & - & \% \\ & 1 & 5 & - & - & \%\end{array}$

Table 1 The parameters are distributed according to a Gaussian with the tails cut off. 


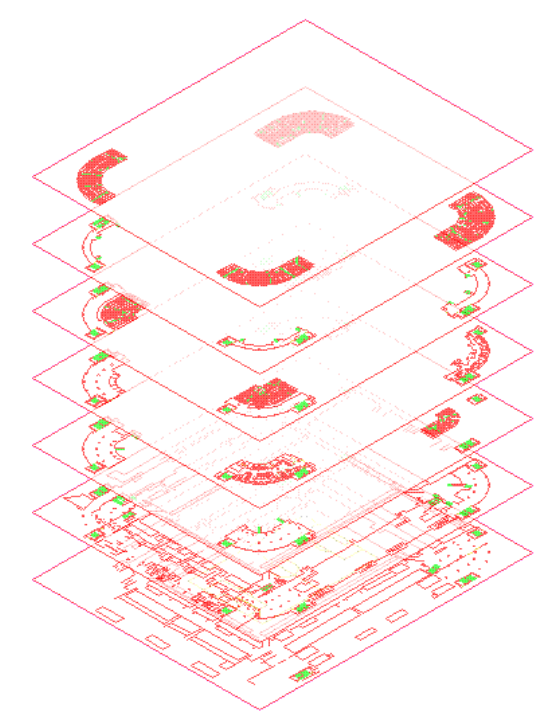

Fig. 3 Sketch of the stadium.

An important information is where congestion occurred. Congestion is easily defined by the local density. We use the following measure: Local congestion is defined by a density that is higher than 4 Persons per square meter. If this density is exceeded for longer than $10 \%$ of the overall egress time, the congestion is called significant. Fig. 1 shows the areas of significant congestion.
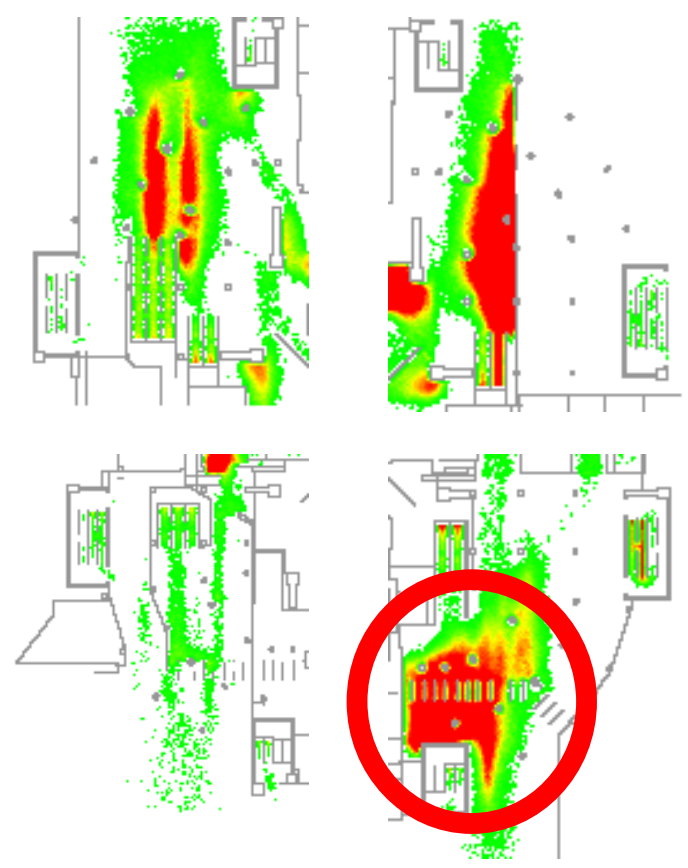

Fig. 4 Analysis of the densities occurred during the simulation. The red areas indicate significant congestion as defined in the text. 
We have investigated three different scenarios concerning the population characteristics:

\subsection{Case 1}

$\begin{array}{lrrccc}\text { Walking speed. } & \text { Min } & \text { Max } & \text { Mean } & \text { StdDev.. } & \begin{array}{c}\text { Units } \\ \text { cells/s }\end{array} \\ \text { Patience } & 4 & 4 & - & - & \text { S } \\ \text { Sway } & 1 & 5000 & - & - & 0.1 \mathrm{a} \\ & & 5 & 3 & 2 & (=4 \mathrm{~cm}) \\ \text { Reaction time } & 0 & 0 & - & - & \mathrm{S} \\ \text { Orientation } & 0 & 0 & - & - & \% \\ \text { Inertia } & 1 & 5 & - & - & \%\end{array}$

\subsection{Case 2}

Walking speed.

$\begin{array}{ccccc}\text { Min } & \text { Max } & \text { Mean } & \text { StdDev.. } & \text { Units } \\ 2 & 5 & 3 & 1 & \text { cells } / \mathrm{s}\end{array}$

\subsection{Case 3}

$\begin{array}{lccccc} & \text { Min } & \text { Max } & \text { Mean } & \text { StdDev.. } & \text { Units } \\ \text { Walking speed. } & 2 & 5 & 3 & 1 & \text { cells/s } \\ \text { Reaction time } & 0 & 30 & 15 & 5 & \mathrm{~S} \\ \text { Orientation } & 0 & 30 & 15 & 5 & \%\end{array}$

The results for the different cases are compared in Fig. 4.

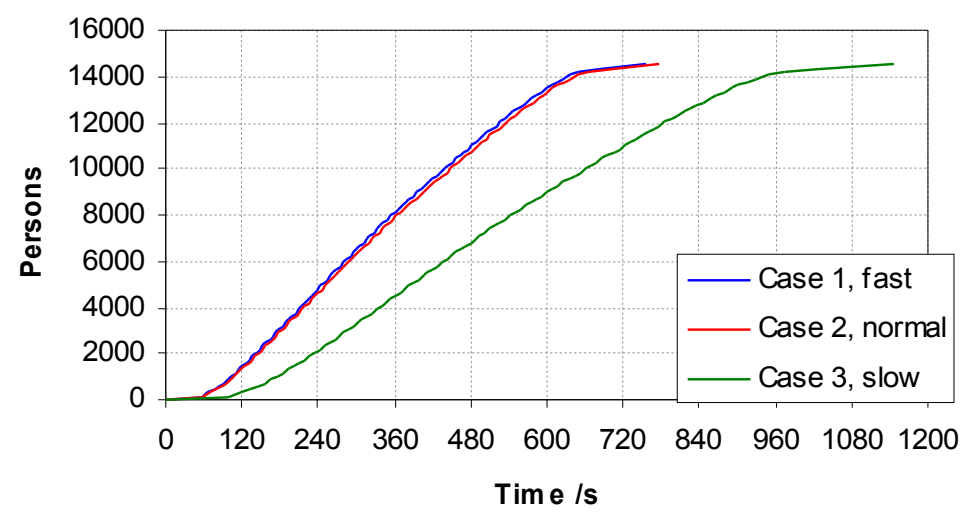

Fig. 5 Results for the different scenarios.

\section{Summary and Conclusions}

We have briefly described a two dimensional cellular automaton model for the simulation of crowd movement and evacuation processes. The model has been applied to simulate the egress from a sports stadium. The results obtained are within those provided by observations from the staff. The approach provides two big advantages: 1) it is rather easy to handle and therefore efficient, 2) animations can be generated from the simulation which 
allow to analyse the evacuation in an intuitive way. Of course, the detailed analysis based on curves like the one shown in figure 4 also provides valuable information for improving procedural or geometrical aspects of the structure.

\section{References}

1. Roth, G., „Gleichtakt im Neuronennetz“, Gehirn und Geist 1, 2002.

2. Weidmann, Ulrich, ,Transporttechnik der Fußgänger“", Schriftenreihe des IVT 90, ETH Zürich, 1992.

3. Yamori, K., "Going with the flow: Micro-macro dynamics in the macrobehavioral patterns of pedestrian crowds", Psychological Review 105(3), 530-557, 2001.

4. IMO, "Interim Guidelines for Evacuation Analyses for New and Existing Passenger Ships", IMO, MSC/Circ. 1033, 2002.

5. AlGadhi, S., H. Mahmassani, and R. Herman, "A speed concentration relation for bi-directional crowd movements with strong interaction”, In: 4.

6. Schreckenberg, M. and S.D. Sharma, "Pedestrian and Evacuation Dynamics", Springer, Berlin, 2002.

7. Burstedde, C., K. Klauck, A. Schadschneider, and J. Zittartz, „Simulation of pedestrian dynamics using a 2-dimensional cellular automaton“, Physica A 295, 507-525, 2001.

8. Fruin, J., "Pedestrian Planning and Design", New York, Metropolitan Association of Urban Designers and Environmental Planners, 1971.

9. Galea, E., "A general approach to validating evacuation models with an application to EXODUS", Journal of Fire Sciences 16(6), 414 - 436, 1998.

10. Hamacher, H. and S. Tjandra, "Mathematical modelling of evacuation problems - a state of the art", In: 4.

11. Helbing D., "Traffic and related self-driven many particle systems", Rev. Mod. Phys. 73(4), 1067-1141, 2001.

12. Henderson, L., "The statistics of crowd fluids", Nature 229, 381-383, 1971.

13. Kirchner, A., H. Klüpfel, K. Nishinari, A. Schadschneider, and M. Schreckenberg (2002).Simulation of competitive egress behaviour. Physica A, 324 (2003). p. $689-697$. .

14. Klüpfel, H., T. Meyer-König, J. Wahle, and M. Schreckenberg, "Microscopic simulation of evacuation processes on passenger ships", In Proc. Fourth Int. Conf. On Cellular Automata for Research and Industry”, pp. 63-71, London, Springer, 2000.

15. Pauls, J., "Movement of People", Chapter 3-13, pp. 3-263-3-285, In: DiNenno, P. (Ed.), "SFPE Handbook of Fire Protection Engineering", ( $2^{\text {nd }}$ ed.), National Fire Protection Association, 1995.

16. TraffGo GmbH, "PedGo Users' Manual (v. 2.1.1)", Duisburg, 2003.

17. Transportation Research Board, "Highway Capacity Manual", Washington D.C., TRB, 1994.

18. Weckman, H., S. Lehtimäki, and S. Männikö, „Evacuation of a theatre: Exercise vs. calculations", Fire and Materials 23(6), 357-361, 1999.

19. Galea, E. (Ed.): Pedestrian and Evacuation Dynamics 2003 - Proceedings of the second international conference. CMS Press, London, 2003.

20. Hubert Klüpfel: A Cellular Automaton Model for Crowd Movement and Egress Simulation. Dissertation, Universität Duisburg-Essen, Duisburg, 2003. http://www.ub.uni-duisburg.de/ETD-db/theses/available/duett-08012003092540/ 